\title{
QUALIDADE MICROBIOLÓGICA E NITRATO EM ÁGUAS MINERAIS E DE POÇOS DE JABOTICABAL-SP
}

\author{
LOPES, Laudicéia Giacometti ${ }^{1}$
} AMARAL, Luiz Augusto do ${ }^{2}$

\begin{abstract}
RESUMO: O presente trabalho teve como objetivos avaliar a qualidade higiênico-sanitária e a concentração de nitratos em águas engarrafadas e de poços particulares utilizadas pela população de Jaboticabal - SP. Para as águas engarrafadas, foram estudadas três marcas, três volumes de embalagens (20 L; 1,5 L; 0,2 L) e cinco lotes. As águas de poços foram analisadas em períodos de seca e de chuva. As variáveis analisadas nos dois casos foram: Pseudomonas aeruginosa, clostridios sulfito-redutores, coliformes totais, Escherichia coli, enterococos, microrganismos aeróbios mesófilos e teores de nitrato. Os resultados evidenciaram que não existe uniformidade de qualidade das águas condicionadas em galões de $20 \mathrm{~L}$, para os diferentes lotes e para as três marcas, o que se deve possivelmente à deficiência do preparo das embalagens para reutilização. Dentre 225 amostras analisadas, $37 \%$ apresentaram-se fora do padrão de potabilidade (Resoluções RDC 274/05 e 275/05). Dentre os sete poços acompanhados, verificou-se que três poços tiveram qualidade microbiológica de sua água influenciada por precipitações pluviométricas e dois apresentaram elevado teor de nitrato. Os resultados evidenciaram que $2,8 \%$ das águas de poço estavam fora dos padrões de potabilidade (Portaria 518/04).
\end{abstract}

Palavras-chave: Análise de risco. Água não-carbonatada. Água de torneira. Água engarrafada. Água potável.

\section{MICROBIOLOGICAL QUALITY AND NITRATE IN MINERAL WATERS AND WELL WATER IN JABOTICABAL-SP, BRAZIL}

\begin{abstract}
The present work aimed the verification of the hygienic-sanitary quality, and the concentration of nitrates in bottled water and from private wells used by the population of Jaboticabal, SP, Brazil. For bottled water, three brand marks, three size bottles $(20 \mathrm{~L}, 1.5 \mathrm{~L}, 0.2 \mathrm{~L})$ and five batches were analyzed. Waters from wells were analyzed in dry and rainy periods. The varieties analyzed in both cases were: Pseudomonas aeruginosa, sulfide reducers clostridium, total coliforms, Escherichia coli, enterococcus, mesophilic aerobic microorganisms and nitrate. The results indicated there's no uniformity in the quality of waters bottled in $20 \mathrm{~L}$ containers for the different batches and for the three brand marks, due, possibly, to deficiency in their preparation for reuse. From 225 analyzed samples, 37\% presented themselves as out of standard of potability (Resolução 274/05 e 275/05). From the seven wells analyzed, Iit was verified that three wells had the microbiological quality of its water influenced by pluvial precipitations and two wells presented high level of nitrate. The results showed that $2.8 \%$ of water from wells were out of potability standard (Portaria 518/04).
\end{abstract}

Keywords: Risk assessment. Non-carbonated water. Tap water. Bottled water. Drinking water.

\section{INTRODUÇÃO}

Atualmente, o Brasil é o sexto maior produtor mundial de água mineral e conta com produção de 5 bilhões de litros por ano (MINISTÉRIO DA SAÚDE, 2006). Além das águas

1 Serviço Autônomo de Água e Esgoto de Jaboticabal. Laudicéia_lopes@globo.com

2 Livre-Docente. Prof. Unesp. Dr. em Saúde Pública. Médico Veterinário. E-mail: lamaral@fcav unesp.br 
minerais, a perfuração de poços em domicílios ou áreas particulares, para consumo primário (alimentação), e que não pertencem à rede pública de abastecimento, também tem aumentado de forma significativa. Atribui-se ao sabor e aos odores causados pela adição de flúor e de cloro nas águas de abastecimento público, o aumento no consumo de águas engarrafadas.

Tal aumento de procura por fontes alternativas de água para consumo primário tem despertado interesse acerca da qualidade dessas. Na microbiota das águas minerais e de poços, coexistem dois grupos de microrganismos diferentes em origem e propriedades: autóctona ou microbiota própria do substrato (GELDREICH, 1998), e alóctona ou microbiota contaminante. Essa microbiota contaminante torna a água importante veículo na transmissão de doenças (FURTADO et al., 1998).

Como exemplo do impacto das águas de consumo alternativo na saúde pública, pode-se citar um surto de cólera ocorrido no ano de 1974, em Portugal, que levou a 2.467 internações e 48 mortes (BLAKE et al., 1977a). Desses, 82 pacientes ingeriram água mineral engarrafada e 36 casos tinham visitado uma clínica abastecida pela mesma fonte utilizada para engarrafamento, cujo lençol freático estava contaminado com Vibrio cholera (BLAKE et al., 1977b).

O monitoramento de patógenos específicos é impraticável e, por esse motivo, supõe-se que indicadores podem estar presentes em maior número e sobreviver tanto quanto microrganismos patogênicos (BURGE; HUNTER, 1990).

Os gêneros Enterobacter, Klebisiella e Citrobacter, pertencentes ao grupo conhecido como coliforme total, apresentam freqüência similar em águas tratadas e não-tratadas, sendo detectados individualmente com a mesma freqüência que microrganismos do gênero Aeromonas (CLARCK et al., 1982). Os microrganismos coliformes podem indicar a presença de poluição fecal de origem humana ou animal, sendo que Escherichia coli indica a ocorrência recente da contaminação.

McFeters et al. (1974) estudaram sobrevivência de bactérias indicadoras e de patógenos entéricos em águas de poços, observando que o grupo coliforme é inativado mais rapidamente que o grupo enterococos. Payment; Franco (1993) estudaram a correlação entre cistos de Giardia lamblia, oocistos de Criptosporidium, vírus entéricos humanos e potenciais indicadores como colifagos e Clostridium perfringens em amostras de várias etapas de tratamento de água; $C$. Perfringens apresentou-se como o melhor indicador da eficiência do tratamento para remoção e inativação desses patógenos.

As águas minerais têm regulamentação dos padrões de potabilidade por meio da Resolução RDC-274 e 275 (BRASIL, 2005a; BRASIL, 2005b), segundo a qual, na fonte e na comercialização, essas não devem apresentar risco à saúde do consumidor e devem estar em conformidade com as características microbiológicas descritas na Tabela 1. 
Tabela 1: Características microbiológicas das águas minerais.

\begin{tabular}{|c|c|c|c|c|c|}
\hline \multirow[b]{2}{*}{ Microrganismo } & \multirow{2}{*}{$\begin{array}{c}\text { Amostra } \\
\text { Indicativa } \\
\text { Limites }\end{array}$} & \multicolumn{4}{|c|}{ Amostra Representativa } \\
\hline & & $\mathbf{n}$ & $\mathbf{C}$ & $\mathbf{M}$ & $\mathbf{M}$ \\
\hline $\begin{array}{l}\text { Escherichia coli ou coliformes } \\
\text { (fecais) }\end{array}$ & Ausência & 5 & 0 & - & Ausência \\
\hline Termotolerantes $100 \mathrm{~mL}^{-1}$ & & & & & \\
\hline Coliformes totais $100 \mathrm{~mL}^{-1}$ & $\begin{array}{l}<1,0 \mathrm{UFC} \\
<1,1 \mathrm{NMP} \\
\text { ou ausência }\end{array}$ & 5 & 1 & $\begin{array}{l}<1,0 \text { UFC; }< \\
\text { 1,1 NMP ou } \\
\text { ausência. }\end{array}$ & $\begin{array}{l}2,0 \mathrm{UFC} \text { ou } \\
\text { 2,2 NMP }\end{array}$ \\
\hline Enterococos $100 \mathrm{~mL}^{-1}$ & $\begin{array}{l}<1,0 \text { UFC; } \\
<1,1 \text { NMP } \\
\text { ou ausência }\end{array}$ & 5 & 1 & $\begin{array}{l}<1,0 \mathrm{UFC} ;< \\
\text { 1,1 NMP ou } \\
\text { ausência. }\end{array}$ & $\begin{array}{l}\text { 2,0 UFC ou } \\
\text { 2,2 NMP }\end{array}$ \\
\hline Pseudomonas aeruginosa $100 \mathrm{~mL}^{-}$ & $\begin{array}{l}<1,0 \text { UFC; } \\
<1,1 \text { NMP } \\
\text { ou ausência }\end{array}$ & 5 & 1 & $\begin{array}{c}<1,0 \text { UFC; < } \\
\text { 1,1 NMP ou } \\
\text { ausência. }\end{array}$ & $\begin{array}{l}\text { 2,0 UFC ou } \\
\text { 2,2 NMP }\end{array}$ \\
\hline $\begin{array}{l}\text { Clostridios sulfito redutores ou } \\
\text { Clostridium perfringens } 100 \mathrm{~mL}^{-1}\end{array}$ & $\begin{array}{l}<1,0 \text { UFC; } \\
<1,1 \text { NMP } \\
\text { ou ausência }\end{array}$ & 5 & 1 & $\begin{array}{l}<1,0 \text { UFC; < } \\
\text { 1,1 NMP ou } \\
\text { ausência. }\end{array}$ & $\begin{array}{l}\text { 2,0 UFC ou } \\
\text { 2,2 NMP }\end{array}$ \\
\hline
\end{tabular}

n: número de unidades de amostra a serem coletadas e analisadas individualmente.

c: número de unidades que pode apresentar resultado entre os valores m e M. Quando o valor de c for igual a 0 (zero), existe apenas um valor de tolerância.

m: limite inferior (mínimo) aceitável.

M: limite superior (máximo) aceitável.

NMP: número mais provável.

UFC: unidades formadoras de colônias.

As fontes de consumo alternativo como minas, poços e drenos são normatizadas pela Portaria do Ministério da Saúde $n^{\circ}$ 518/04 (BRASIL, 2004). Um dos aspectos abordados nessa portaria consiste na tolerância da presença de coliformes totais, na ausência de Escherichia coli, para amostras individuais de poços, fontes, nascentes e outras formas de abastecimento sem distribuição canalizada. Essa legislação exige a contagem de bactérias heterotróficas e estabelece $500 \mathrm{UFC} \mathrm{mL}^{-1}$ como o limite para que a fonte seja considerada com comprometimento sanitário.

Diante disso, o presente trabalho utilizou coliformes totais, Escherichia coli, enterococos, clostridios sulfito redutores, Pseudomonas aeruginosa e microrganismos aeróbios mesófilos como indicadores microbiológicos. Nitrato, oriundo de decomposição de matéria orgânica e com alta solubilidade em água, foi utilizado como indicador químico de qualidade de água. Foram avaliadas águas minerais (três marcas, três volumes de embalagens $(20 \mathrm{~L}, 1,5 \mathrm{~L}, 0,2$ 
L)) e cinco lotes, e águas de poços (sete poços em período de chuva e seca), utilizados para consumo no município de Jaboticabal, São Paulo.

\section{MATERIAL E MÉTODOS}

\section{1 ÁGUA MINERAL}

Foram analisados três marcas (A, B e C) e três volumes de embalagens $(0,2 \mathrm{~L}$ - copo, 1,5 L - garrafa e $20 \mathrm{~L}$ - galão) de polipropileno, sendo copo e garrafa descartáveis e galão reutilizável. Para cada condição (por exemplo: marca A, copos), foram analisadas cinco amostras de cinco lotes, totalizando 25 lotes por condição e 225 amostras no estudo. As amostras foram adquiridas em supermercados, na cidade de Jaboticabal - SP.

\section{2 ÁGUAS DE POÇO}

Foram analisadas águas de sete poços, sendo quatro rasos e três profundos, todos localizados no perímetro urbano do município de Jaboticabal - SP, e fornecedores de água para consumo humano para uma única residência ou para a população. Nesse caso, foram coletadas cinco amostras de cada poço em período de seca e cinco amostras em período de chuva, totalizando 70 amostras.

Os poços 1; 2; 3 e 4 consistiam em poços rasos localizados em residências e eram utilizados como fonte de água para beber. Em todos esses casos, o abastecimento doméstico era realizado com auxílio de bombas.

Os poços 5 e 6 consistiam em poços profundos e, embora localizados em propriedades particulares, forneciam água gratuitamente para a população de Jaboticabal, que a utilizava para o consumo primário.

O poço 7 consistia em um poço profundo, localizado em área pública, e fornecia água, gratuitamente, para o consumo primário da população.

A profundidade e a localização dos poços são mostradas na Tabela 2.

Tabela 2: Profundidade e localização dos poços analisados.

\begin{tabular}{|c|c|c|c|c|}
\hline \multirow[b]{2}{*}{ Poço } & \multirow{2}{*}{$\begin{array}{c}\text { Profundidade } \\
\text { (m) }\end{array}$} & \multicolumn{3}{|c|}{ Localização } \\
\hline & & Latitude & Longitude & Altitude (m) \\
\hline 1 & 36 & $2115 ' 57.36621$ "S & 48 18’21.70146”W & 618 \\
\hline 2 & 35 & 21 15'46.48489”S & 48 18'35.53107’W & 599 \\
\hline 3 & 32 & 2114 '45.96201”S & 48 19'14.82676”W & 603 \\
\hline 4 & 35 & 21 14'12.79079"S & 48 19'41.89287’'W & 648 \\
\hline 5 & 120 & $2115 ' 12.79708 ” S$ & 48 19'03.73115”W & 573 \\
\hline 6 & 130 & $2115^{\prime} 42.68275^{\prime} \mathrm{S}$ & 48 19’31.47649”W & 632 \\
\hline 7 & 458 & $2114^{\prime} 21.75503 ” S$ & 48 17’33.30188”W & 574 \\
\hline
\end{tabular}

Determinação: Departamento de Engenharia Rural, FCAV/UNESP.

Nucleus, v. 5. n. 1 , abr. 2008 


\subsection{MÉTODO EXPERIMENTAL}

As águas, tanto minerais quanto de poços, foram amostradas em frascos de $500 \mathrm{~mL}$ estéreis. Para embalagens com 0,2 L, preparou-se amostra composta, fazendo a agitação de três unidades e coleta das mesmas em frasco de $500 \mathrm{~mL}$ estéril. Não houve padronização do tempo entre a data do engarrafamento e a data de análise, considerando-se como pertencentes ao mesmo lote, amostras que tinham sido engarrafadas no mesmo dia.

As análises foram conduzidas no Laboratório de Alimentos de Origem Animal e Água, localizado no Departamento de Medicina Veterinária Preventiva e Reprodução Animal, da Faculdade de Ciências Agrárias e Veterinárias, UNESP, Campus de Jaboticabal, de acordo com os métodos descritos a seguir:

- Clostridios sulfito redutores (SARTORY et al., 1993): $100 \mathrm{~mL}$ de cada amostra de água foram filtrados através de um aparelho de filtração, contendo membranas filtrantes com porosidade $0,45 \mu \mathrm{m}$. Depois da filtração, as membranas foram transferidas para placas de Petri, contendo meio TSC preparado com Ágar Base Perfringens (triptose $15 \mathrm{~g} \mathrm{~L}^{-1}$, peptona de soja 5,0 $\mathrm{g} \mathrm{L}^{-1}$, extrato de carne 5,0 $\mathrm{g} \mathrm{L}^{-1}$, extrato de levedura 5,0 $\mathrm{g} \mathrm{L}^{-1}$, metabissulfito de sódio $1,0 \mathrm{~g} \mathrm{~L}$ , citrato de ferro amoniacal 1,0 $\mathrm{g} \mathrm{L}^{-1}$ e ágar 14,0 $\mathrm{g} \mathrm{L}^{-1}$ ) e D-Cicloserina (Oxoid), de acordo com instruções do fabricante do meio. As placas foram incubadas abertas e intercaladas em jarra de anaerobiose, contendo Anaerobac (Probac), para geração do ambiente adequado. Utilizouse a temperatura de $35^{\circ} \mathrm{C}$ por 24 horas. As colônias negras foram contadas como Unidades Formadoras de Colônias, UFC $100 \mathrm{~mL}^{-1}$, da amostra.

- Coliformes totais e Escherichia coli (APHA, 1992): utilizou-se o método do substrato cromogênico, por meio do qual $100 \mathrm{~mL}$ de amostra é misturado com o meio Colilert (Idexx). Após agitação e completa dissolução, a mistura foi transferida para cartela Quanti-Tray/2000, selada em seladora Quanti-Tray. Após incubação das cartelas, feita a $35^{\circ} \mathrm{C}$ por 24 horas, foram contadas as células que desenvolveram coloração amarela, e, consultando a tabela de Número Mais Provável (NMP), os resultados foram expressos em NMP $100 \mathrm{~mL}^{-1}$. A exposição da mesma cartela à luz ultravioleta de $365 \mathrm{~nm}$ possibilitou a contagem de células com fluorescência, produzida quando Escherichia coli utiliza $\beta$-gluconidase para metabolizar MUG (4 metil umberliferil $\beta$-d-glucoronídeo), que foram expressas, após consultada a tabela de Número Mais Provável, como NMP $100 \mathrm{~mL}^{-1}$.

- Enterococos (APHA, 1992): para a contagem de enterococos foi conduzida com o método do substrato cromogênico, seguindo instruções do fabricante do meio. Foram transferidos $100 \mathrm{~mL}$ de amostra para frasco estéril de $250 \mathrm{~mL}$ e adicionado o meio Enterolert (Idexx). Após agitação e completa dissolução, a mistura foi transferida para cartela Quanti-Tray/2000 selada, utilizando-se da seladora Quanti-Tray. Após incubação das cartelas em temperatura de $42{ }^{\circ} \mathrm{C}$ por 24 horas, foram contadas as células que desenvolveram fluorescência quando exposta à luz ultravioleta de $365 \mathrm{~nm}$ e, consultando a tabela de Número Mais Provável (NMP), os resultados foram expressos em NMP $100 \mathrm{~mL}^{-1}$. 
- Pseudomonas aeruginosa (APHA, 1992): $100 \mathrm{~mL}$ de cada amostra de água foram filtrados através de um aparelho de filtração Millipore, contendo membranas filtrantes com porosidade de $0,45 \mu \mathrm{m}$. No teste preliminar, após a filtração, a membrana foi colocada em placa de Petri contendo Ágar M - PA - C (BBL $\left.{ }^{\mathrm{TM}}\right)$; invertendo-se as placas em seguida e incubando a $41 \pm 0,5^{\circ} \mathrm{C}$, durante 72 horas. Após a incubação, com auxílio de contador de colônias, foram contadas as colônias com 0,8 a 2,2 mm de diâmetro, achatadas com bordas claras e o centro de verde a marrom. No teste para confirmação, foi feita a semeadura de 3 a 5 colônias isoladas em M - PA - C (BBL $\left.{ }^{\mathrm{TM}}\right)$ em estrias sobre a superfície de Ágar Leite: $100 \mathrm{~g}$ de leite desnatado instantâneo (Nestlé), $500 \mathrm{~mL}$ de água (solução A) e 12,5 g de caldo nutriente (Oxoid), 2,5 g de cloreto de sódio (Vetec), 15,0 g de ágar (Merck) e $500 \mathrm{~mL}$ de água (solução B), misturandose as soluções A e B depois de serem esterilizadas separadamente. A incubação foi conduzida a $35 \pm 1,0{ }^{\circ} \mathrm{C}$, durante 24 horas. Considerou-se confirmatória a produção de um pigmento amarelo esverdeado, o qual é produto da hidrólise da caseína (presente no meio ágar leite) por Pseudomonas aeruginosa. O resultado foi expresso como Unidades Formadoras de Colônias, UFC $100 \mathrm{~mL}^{-1}$, da amostra.

- Microrganismos aeróbios mesófilos (APHA, 1992): foi utilizada a técnica "pour plate" em que $1 \mathrm{~mL}$ da amostra ou de suas diluições foi transferido para placas de Petri estéreis e vertidos 15 a $17 \mathrm{~mL}$ de agar PCA. Após homogeneização e solidificação do Ágar, as placas invertidas foram incubadas a $35 \pm 0,5{ }^{\circ} \mathrm{C}$ por 48 horas.

- Nitrato: utilizou-se do método de redução por cádmio (APHA, 1992), com adaptação citada pela HACH (s.d.). Nessa, o volume de $25 \mathrm{~mL}$ da amostra foi medido diretamente na cubeta e adicionou-se NitraVer 5 Nitrate Reagent Powder Pillow (Hach), seguido de agitação durante 1 minuto. Depois de repouso de 5 minutos, foi feita a leitura da amostra, expressa em

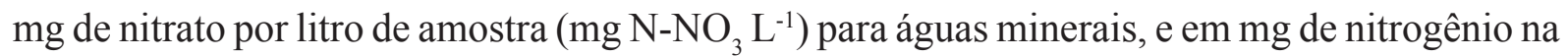

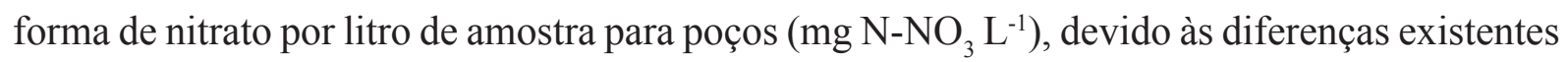
na legislação (Portaria 518/04, água de poço, e Resoluções 275/05 e 274/05, águas minerais).

\section{RESULTADOS E DISCUSSÃO}

\section{1 ÁGUA MINERAL}

Os resultados da análise dos indicadores microbiológicos e químicos de qualidade de água referentes às águas minerais avaliadas são mostrados na Tabela 3.

Observando-se os dados mostrados na Tabela 3, nota-se que, para a marca A, os galões de $20 \mathrm{~L}$ apresentaram, na maioria, os indicadores microbiológicos (exceto E. coli). Tal fato torna esse tipo de embalagem um agente de depreciação da qualidade da água para essa marca, seguida dos copos e, por fim, das garrafas. Nesse caso, as contagens elevadas de $P$. aeruginosa e mesófilos encontrados em copos originaram somente de um, dentre cinco lotes avaliados. Tal situação mostra a descontinuidade com relação à qualidade da água industrializada. 
Tabela 3: Contagem média de coliforme total (NMP $100 \mathrm{~mL}^{-1}$ ), Escherichia coli (NMP 100 $\mathrm{mL}^{-1}$ ), clostridium sulfito redutores (UFC $100 \mathrm{~mL}^{-1}$ ), enterococos (NMP $100 \mathrm{~mL}^{-1}$ ), Pseudomonas aeruginosa (UFC $100 \mathrm{~mL}^{-1}$ ), mesófilos (UFC mL $\mathrm{mL}^{-1}$ ) e concentração média de nitrato $\left(\mathrm{mg} \mathrm{N}^{-N_{3}} \mathrm{~L}^{-1}\right)$ em águas minerais comercializadas em Jaboticabal - SP.

\begin{tabular}{lcccccccccc}
\hline \multirow{2}{*}{ Indicadores } & \multicolumn{3}{c}{ A } & \multicolumn{4}{c}{ Marca } \\
\cline { 2 - 10 } & Copo & Garrafa & Galão & Copo & Garrafa & Galão & Copo & Garrafa & Galão \\
\hline Microbiológicos & & & & & & & & & \\
Coliforme total & 0,00 & 6,68 & 2,92 & 0,04 & 0,00 & 25,56 & 0,16 & 1,57 & 5,50 \\
Escherichia & 0,00 & 0,00 & 0,00 & 0,00 & 0,00 & 0,00 & 0,00 & 0,00 & 0,00 \\
coli & 0,00 & 0,00 & 0,08 & 0,00 & 0,00 & 0,00 & 0,00 & 0,00 & 0,18 \\
ClostridiumSR & 0,08 & 0,00 & 3,80 & 0,00 & 0,00 & 18,10 & 0,12 & 0,08 & 250,67 \\
Enterococos & 0,0 Peudomonas & 31,44 & 0,00 & 21,8 & 0,00 & 0,80 & 0,00 & 0,00 & 0,12 & 4,96 \\
$\begin{array}{l}\text { aeruginosa } \\
\text { Mesófilos }\end{array}$ & 5593 & 6 & 1949 & 514 & 3222 & 12515 & 48615 & 15505 & 12743 \\
Químico & & & & & & & & & \\
Nitrato & 4,6 & 5,0 & 5,5 & 9,3 & 9,5 & 9,5 & 11,8 & 11,3 & 9,7 \\
\hline
\end{tabular}

Para a marca B, observa-se a mesma tendência notada para a marca A, ou seja, as águas acondicionadas em galões retornáveis apresentaram maior número de indicadores que as águas acondicionadas em copos e garrafas. A única ressalva é feita para $P$. aeruginosa, que esteve presente nas águas das garrafas e ausente em águas de galões.

As águas de galões de $20 \mathrm{~L}$ da marca $\mathrm{C}$ também apresentaram qualidade inferior, comparadas às águas de copos e garrafas. Nesse caso, dois indicadores microbiológicos, coliformes totais e enterococos, estavam presentes em todos os tipos de embalagens avaliadas. Tal fato sugere que, além de deficiências com relação às boas práticas de engarrafamento, a fonte de água pode ter passado por contaminação antes da surgência ou captação. Outro aspecto relevante consiste no fato de que a tendência observada para contagem de mesófilos na marca $\mathrm{C}$ (contagem em água de copo maior que em água de galão) coincide com os resultados obtidos para a marca A.

Para nitrato, as marcas A e B apresentaram concentrações maiores em águas de galões, as quais confirmam as informações fornecidas pelos indicadores microbiológicos. Avaliando a diferença entre as marcas, a marca $\mathrm{C}$ apresentou concentrações maiores que as demais, embora nenhuma amostra tenha excedido o limite estabelecido na legislação vigente de $50 \mathrm{mg} \mathrm{N}-\mathrm{NO}_{3}$ $\mathrm{L}^{-1}$ (BRASIL, 2005b). Tal ocorrência de nitrato, coincidente com a presença de coliformes totais e enterococos nas amostras de todas as embalagens, confirma a hipótese de que a fonte utilizada pela marca $\mathrm{C}$ é mais vulnerável que as fontes utilizadas pelas demais marcas avaliadas.

Considerando os critérios expressos nas Resoluções RDC-274 e 275 (BRASIL, 2005a; BRASIL, 2005b), a percentagem de amostras fora do padrão, de acordo com os indicadores analisados, foi expressa por tipo de embalagem, para as três marcas, conforme Figura 1. 


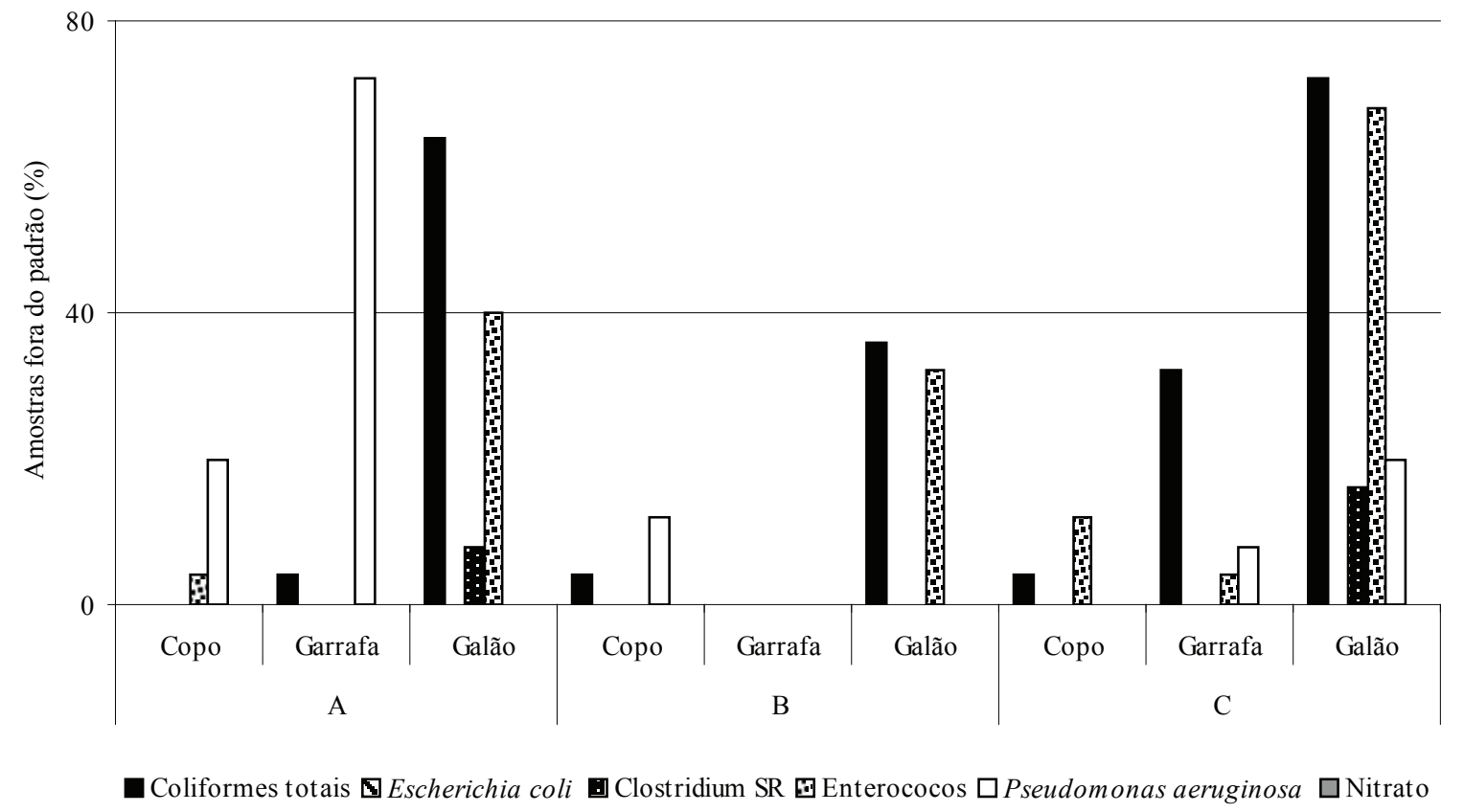

Figura 1: Percentagem de amostras em copos, garrafas e galões das marcas A, B e C, fora dos padrões expressos nas Resoluções RDC-274 e 275 (BRASIL, 2005a; BRASIL, 2005b).

Os resultados apresentados na Figura 1 mostram que, para a marca A, 4\% dos copos estavam fora do padrão por apresentarem a contagem de enterococos, e $20 \%$ por apresentarem Pseudomonas aeruginosa. Cerca de $72 \%$ das garrafas estavam fora do padrão devido à $P$. aeruginosa, e 4\% devido a coliformes totais. Para os galões, $64 \%$ excederam o padrão devido à presença de coliformes totais, $8 \%$ de Clostridium sulfito redutores, e $40 \%$, enterococos.

$\mathrm{Na}$ marca B, 4\% dos copos continham coliformes totais, e 12\%, P. aeruginosa. Para garrafas, a presença de $P$. aeruginosa foi menor que $1 \%$, e para os galões, o padrão foi excedido devido a coliformes totais $(36 \%)$ e enterococos $(32 \%)$.

Os copos da marca C apresentaram coliformes totais (4\%) e enterococos (12\%); as garrafas apresentaram coliformes totais $(32 \%)$, enterococos $(4 \%)$ e P. aeruginosa (8\%). Os galões dessa marca apresentaram coliformes totais $(72 \%)$, clostridium sulfito redutores $(16 \%)$, enterococos (68\%) e P. aeruginosa (20\%).

Os resultados obtidos no estudo conduzido em Jaboticabal - SP foram comparados com os resultados, descritos na literatura, em outros países (Inglaterra, 1.082 amostras e Canadá, 357 amostras) e são apresentados na Figura 2. 


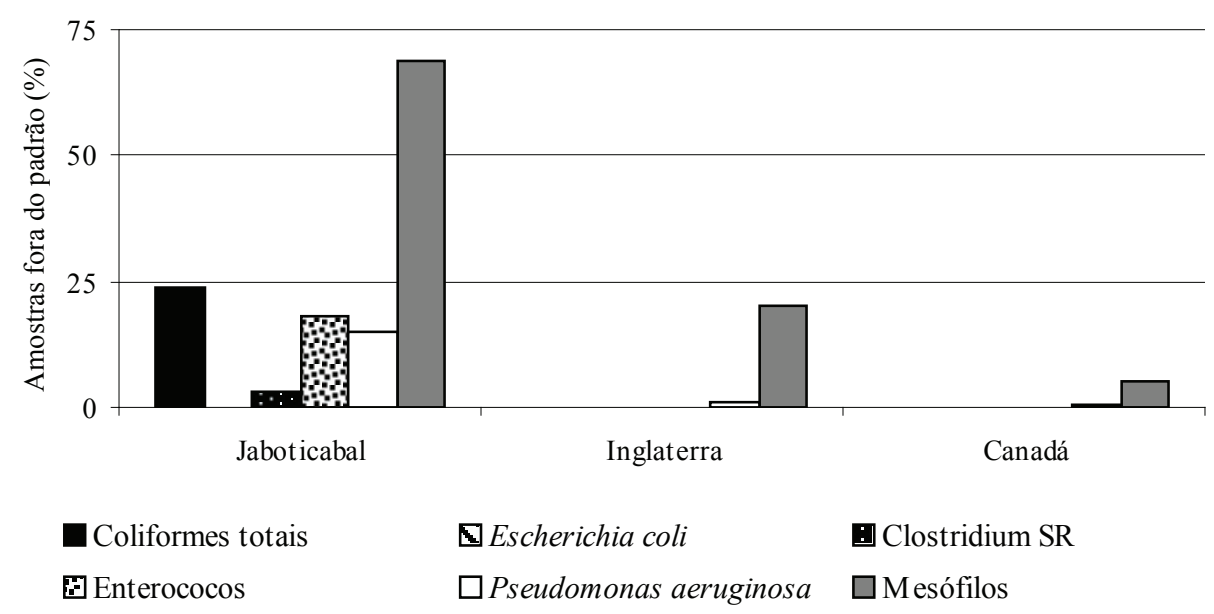

Figura 2: Comparação entre a percentagem de amostras de água mineral fora do padrão de Jaboticabal - SP, da Inglaterra (FEWTRELL et al. 1997) e do Canadá (WARBURTON et al., 1998).

Existem algumas divergências nas legislações que abordam a qualidade de águas minerais em diferentes países. No Brasil, os microrganismos aeróbios mesófilos não são controlados em águas minerais, portanto, para o caso de Jaboticabal, considerou-se o limite de 500 UFC mL1, utilizado para águas de abastecimento público (BRASIL, 2004). O trabalho conduzido na Inglaterra relata apenas a percentagem de unidades amostrais, contendo número de mesófilos acima de 1.000 UFC mL-1 (FEWTRELL et al., 1997), e, no Canadá, foram relatadas as amostras contendo entre 10 e $10.000 \mathrm{UFC} \mathrm{mL}^{-1}$ (WARBURTON et al., 1998). De acordo com os últimos autores, a legislação canadense refere-se ao limite de $10.000 \mathrm{UFC} \mathrm{mL}^{-1}$ como sendo o patamar a partir do qual ocorre risco à saúde pública. No estudo desenvolvido em Jaboticabal - SP, 27\% das amostras analisadas apresentaram mesófilos acima de $10.000 \mathrm{UFC} \mathrm{mL}^{-1}$.

Os resultados obtidos para as águas consumidas em Jaboticabal estão aquém dos resultados obtidos para a Grécia, onde 1.527 amostras apresentaram 13,95\% fora do padrão, considerando todos os indicadores analisados: bactérias heterotróficas, coliformes totais, Escherichia coli, Enterococcus spp e Pseudomonas aeruginosa (VANIERI et al., 2006). As amostras de Jaboticabal apresentaram o número de amostras fora do padrão próximo do observado na Índia, onde, dentre 105 amostras, cerca de 40\% excederam o limite do padrão de potabilidade indiano (JEENA et al., 2006).

As diferenças existentes entre as águas minerais consumidas em Jaboticabal e as águas consumidas em outras localidades, cuja qualidade é descrita pela literatura, conforme mostrado na Figura 2, podem ser atribuídas a diversos fatores.

O primeiro fator consiste no tipo de material utilizado para a fabricação da embalagem. Segundo Fewtrell et al. (1997), as embalagens de vidro são melhores que embalagens plásticas; dentre as embalagens plásticas, as incolores são melhores que as coloridas. De acordo com os autores, as embalagens coloridas bloqueiam a ação da radiação ultravioleta que atua como 
desinfetante e inibe o crescimento bacteriano. Portanto, o tipo de material da embalagem de 20 L (plástico colorido) pode contribuir para o crescimento bacteriano.

A aplicação de boas práticas de fabricação pode ser outro fator a colaborar com as divergências observadas nesses estudos. De acordo com Warburton et al. (1998), essa é a principal causa das diferenças de qualidade entre águas minerais distintas. Segundo os autores, entre as práticas permitidas no Canadá estão a filtração e a desinfecção com radiação ultravioleta; a condução adequada das mesmas levaria ao acréscimo de qualidade nas águas minerais comercializadas. A utilização de práticas desinfetantes adicionais poderia contribuir para a melhoria da qualidade dessas águas. Entre essas práticas, estariam a ozonização, que tem a capacidade de destruir biofilmes formados na superfície interna das embalagens, associada à radiação ultravioleta, carbonatação (promove redução de pH) ou ultrafiltração.

A influência do tipo de embalagem e do tipo de engarrafamento também foi observada por Obiri-Danso, Okore-Hanso; Jones (2003), em águas vendidas em Gana. Nesse caso, as amostras que apresentaram maior contagem de bactérias heterotróficas foram as embaladas manualmente em garrafas de polietileno $\left(2 \times 10^{3}\right.$ a $\left.7 \times 10^{12} \mathrm{UFC}^{-1}\right)$ e as embaladas industrialmente em sacos (2 a $\left.6 \times 10^{5} \mathrm{UFC} \mathrm{mL}^{-1}\right)$. As melhores amostras foram encontradas embaladas industrialmente em galões (1 a $460 \mathrm{UFC} \mathrm{mL}^{-1}$ ).

Em adição ao tipo de material e à aplicação de boas práticas de fabricação, alguns estudos mostram que a população bacteriana passa por crescimento entre a primeira e segunda semana após o envase (BISCHOFBERGER et al., 1990). Sendo assim, a qualidade microbiológica seria dependente do shelf life, ou seja, do tempo de prateleira das águas engarrafadas. Neste estudo, o tempo de prateleira dos cinco lotes analisados foi comparado com a contagem de mesófilos, e os resultados são apresentados na Tabela 4.

Nota-se, por meio dos resultados expressos na Tabela 4, que, para os lotes estudados, não houve relação entre o tempo de prateleira (shelf life) e a população bacteriana presente nas águas. Como exemplo, podem-se citar as garrafas e galões da marca A, em que águas das garrafas, com períodos de prateleira maiores de duas semanas, apresentaram contagem menor do que galões com período de prateleira menor do que uma semana. Tais resultados indicam que, no presente estudo, o período de prateleira não foi responsável pelas elevadas contagens de mesófilos observadas. 
Tabela 4: Shelf life (tempo de prateleira) e contagem de mesófilos para os cinco lotes de copos, garrafas e galões das marcas A, B e C.

\begin{tabular}{|c|c|c|c|c|c|c|c|}
\hline \multirow[b]{2}{*}{ Embalagem } & \multirow[b]{2}{*}{ Lote } & \multicolumn{2}{|c|}{ Marca A } & \multicolumn{2}{|c|}{ Marca B } & \multicolumn{2}{|c|}{ Marca C } \\
\hline & & $\begin{array}{c}\text { Shelf } \\
\text { life } \\
\text { (dias) }\end{array}$ & $\begin{array}{l}\text { Mesófilos } \\
\left(\mathrm{UFC} \mathrm{mL}^{-1}\right)\end{array}$ & $\begin{array}{l}\text { Shelf } \\
\text { life } \\
\text { (dias) }\end{array}$ & $\begin{array}{l}\text { Mesófilos } \\
\left(\mathrm{UFC} \mathbf{m L}^{-1}\right)\end{array}$ & $\begin{array}{l}\text { Shelf } \\
\text { life } \\
\text { (dias) }\end{array}$ & $\begin{array}{l}\text { Mesófilos } \\
\left(\mathrm{UFC} \mathrm{mL}^{-1}\right)\end{array}$ \\
\hline \multirow{5}{*}{ Copo } & 1 & 13 & 17066 & 28 & 95916 & 9 & 1066 \\
\hline & 2 & 15 & 3718 & 37 & 15114 & 32 & 6123 \\
\hline & 3 & 49 & 1846 & 38 & 6105 & 53 & 3094 \\
\hline & 4 & 51 & 4576 & 70 & 0 & 68 & 61200 \\
\hline & 5 & 84 & 699 & 114 & 226 & 101 & 37050 \\
\hline \multirow{5}{*}{ Garrafa } & 1 & 23 & 1 & 11 & 12369 & 25 & 27266 \\
\hline & 2 & 24 & 1 & 24 & 12058 & 30 & 23260 \\
\hline & 3 & 45 & 10 & 33 & 7723 & 31 & 12480 \\
\hline & 4 & 58 & 6 & 57 & 1401 & 35 & 12700 \\
\hline & 5 & - & - & 103 & 120000 & 55 & 1820 \\
\hline \multirow{5}{*}{ Galão } & 1 & 1 & 820 & 1 & 0 & 3 & 1002 \\
\hline & 2 & 4 & 280 & 1 & 100 & 6 & 17900 \\
\hline & 3 & 5 & 3554 & 6 & 45730 & 7 & 6509 \\
\hline & 4 & 6 & 270 & 9 & 22620 & 9 & 14900 \\
\hline & 5 & 6 & 6768 & 9 & 34280 & 14 & 3748 \\
\hline
\end{tabular}

Os resultados expressos na Tabela 4 contrariam o que foi encontrado por Korzeniewska et al. (2005). Nesse caso, os autores observaram que o aumento do número de amostras fora do padrão sobe de $29 \%$ para $47 \%$, quando estocadas por 3 e 14 dias, respectivamente. Segundo os mesmos, a temperatura de estocagem exerce pouca influência, e fatores que exercem maior influência são marca, tempo de estocagem e adição de gás carbônico.

\section{2 ÁGUA DE POÇO}

Os resultados referentes aos indicadores microbiológicos e químicos monitorados em água de poço utilizados para consumo pela população de Jaboticabal - SP, em período de chuva e seca, são mostrados na Tabela 5.

Por meio dos resultados obtidos, podem-se classificar os poços monitorados em três tipos, de acordo com a dinâmica de contaminação. A primeira classe, composta pelos poços 1; 3 e 4, destaca-se pelo aumento da contagem de indicadores em período de chuva. Nesse caso, a infiltração pode ser o principal mecanismo de transporte de contaminantes para a fonte. A construção de barreiras protetoras como o calçamento ao redor da captação, a elevação da boca do poço em relação ao nível do solo e o afastamento de atividades de risco poderiam trazer contribuições positivas para a qualidade de água dos mesmos. 
Tabela 5: Contagem média de coliforme total (NMP $100 \mathrm{~mL}^{-1}$ ), Escherichia coli (NMP $100 \mathrm{~mL}^{-1}$ ), clostridium sulfito redutores (UFC $100 \mathrm{~mL}^{-1}$ ), enterococos (NMP $100 \mathrm{~mL}^{-1}$ ), Pseudomonas aeruginosa (UFC $100 \mathrm{~mL}^{-1}$ ), mesófilos UFC $\mathrm{mL}^{-1}$ ) e

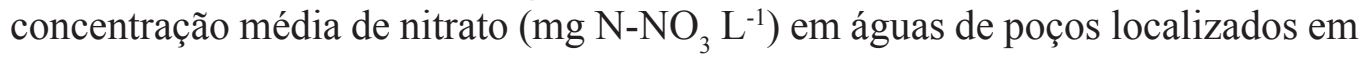
Jaboticabal - SP.

\begin{tabular}{|c|c|c|c|c|c|c|c|c|c|c|c|c|c|c|}
\hline \multirow{3}{*}{ Indicadores } & \multicolumn{14}{|c|}{ Poço } \\
\hline & \multicolumn{2}{|c|}{1} & \multicolumn{2}{|c|}{2} & \multicolumn{2}{|c|}{3} & \multicolumn{2}{|c|}{4} & \multicolumn{2}{|r|}{5} & \multicolumn{2}{|c|}{6} & \multicolumn{2}{|c|}{7} \\
\hline & $\mathbf{C}$ & $\mathbf{S}$ & $\mathbf{C}$ & $\mathbf{S}$ & $\mathbf{C}$ & $\mathbf{S}$ & $\mathbf{C}$ & $\mathbf{S}$ & $\mathbf{C}$ & $\mathbf{S}$ & $\mathbf{C}$ & $\mathbf{S}$ & $\mathbf{C}$ & $\mathbf{S}$ \\
\hline Microbiológicos & & & & & & & & & & & & & & \\
\hline Coliforme total & 11,7 & 0,0 & 1,9 & 14,6 & 3,3 & 0,2 & 7,8 & 0,0 & 0,2 & 0,2 & 30,9 & 282,8 & 3,7 & 4,2 \\
\hline Escherichia coli & 0,0 & 0,0 & 0,0 & 0,2 & 0,0 & 0,0 & 0,0 & 0,0 & 0,0 & 0,0 & 0,0 & 0,2 & 0,0 & 0,0 \\
\hline Clostridium SR & 0,0 & 0,0 & 0,0 & 0,0 & 0,0 & 0,0 & 0,0 & 0,0 & 0,0 & 0,0 & 0,0 & 0,0 & 0,0 & 0,0 \\
\hline Enterococos & 0,0 & 0,0 & 0,0 & 1,6 & 0,0 & 0,0 & 0,8 & 0,0 & 0,0 & 0,0 & 21,8 & 1,2 & 8,2 & 0,0 \\
\hline P. aeruginosa & 0,0 & 0,0 & 0,0 & 0,0 & 0,0 & 0,0 & 0,0 & 0,0 & 0,0 & 0,0 & 0,0 & 0,0 & 0,0 & 0,0 \\
\hline Mesófilos & 90 & 389 & 3 & 79 & 64 & 202 & 243 & 115 & 1 & 25,4 & 3 & 39 & 9 & 286 \\
\hline Químico & & & & & & & & & & & & & & \\
\hline Nitrato & 0,7 & 1,1 & 0,9 & 1,8 & 5,7 & 5,7 & 0,7 & 1,6 & 5,5 & 6,7 & 0,9 & 1,1 & 1,3 & 1,5 \\
\hline
\end{tabular}

Onde: $\mathrm{C}$, chuva e $\mathrm{S}$, seca.

A segunda classe é composta pelo poço 2, que apresentou aumento da contagem de indicadores em período de seca. A dinâmica de contaminação dessa fonte difere das anteriores e é governada pelo mecanismo de concentração-diluição. No período de chuva, a infiltração promove a diluição das espécies presentes e, em período de seca, a redução do volume de água promove a concentração de contaminações anteriores.

Para o poço 5, observou-se que não há variação na qualidade da água entre diferentes períodos do ano. Tal fato, juntamente com a contagem baixa obtida para os parâmetros avaliados, mostra que essa fonte está protegida contra contaminações microbiológicas.

Para os poços 6 e 7, a contagem de coliformes totais foi maior em período de seca. No entanto, em período de chuva, foram observados enterococos que, em período de seca, estavam ausentes para o poço 7 , e em pouca quantidade para o poço 6 . Portanto, nesse caso, o mecanismo que governa a qualidade da água não ficou exatamente esclarecido.

O trabalho desenvolvido por Amaral (1992), em poços utilizados para abastecimento público de Jaboticabal, encontrou maior contaminação dos mesmos em períodos de chuva para coliformes totais $\left(4,4 \mathrm{NMP} 100 \mathrm{~mL}^{-1}\right)$ que em período de seca $\left(3,5 \mathrm{NMP} 100 \mathrm{~mL}^{-1}\right)$. Nesta pesquisa, enterococos estiveram presentes em chuva em níveis menores $\left(1,5 \mathrm{NMP} \mathrm{mL}^{-1}\right)$ que em período de seca $\left(2,0 \mathrm{NMP} \mathrm{mL}^{-1}\right)$. Tais resultados coincidem com a tendência observada para os poços 6 e 7 .

Para mesófilos, exceto para o poço 4, todos os poços estudados apresentaram contagem maior em período de seca, caracterizando concentração de nutrientes e multiplicação da microbiota natural ou eventualmente contaminante.

As concentrações de nitrato foram maiores para período de seca em todos os poços estudados, mostrando que a concentração desse contaminante pela redução de vazão das 
fontes é o mecanismo que prevalece. Embora nenhuma amostra tenha excedido o limite de $10 \mathrm{mg} \mathrm{N}-\mathrm{NO}_{3} \mathrm{~L}^{-1}$ estabelecido na legislação (BRASIL, 2004), observou-se que os poços 3 e 5 apresentam concentrações maiores que os demais. Destaca-se que, tanto o poço 5 quanto o poço 3 , encontram-se em regiões de urbanização recente, anteriormente utilizadas para atividades agrícolas.

A freqüência de amostras fora do padrão expresso na Portaria 518/04 (BRASIL, 2004) é expressa na Figura 3, separadamente por tipo de indicador.

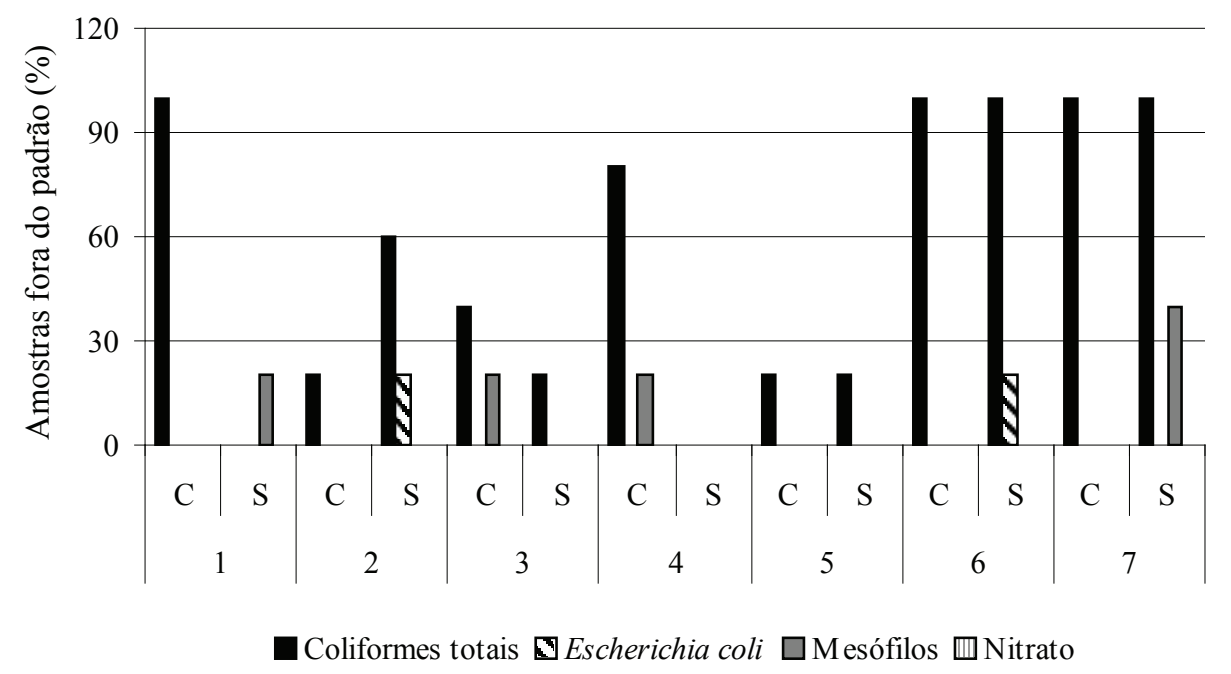

Figura 3: Percentagem de amostras de poços em período de chuva (C) e seca (S), fora do padrão para coliformes totais, E. coli e nitrato, de acordo com os critérios expressos na Portaria 518 (BRASIL, 2004).

Nota-se, por meio da Figura 3, que, no caso dos poços 6 e 7, todas as amostras analisadas continham coliformes totais nos períodos de chuva e seca. Tal fato repetiu-se para o poço 1 somente em período de chuva. Para o poço 2, 60\% das amostras de seca também apresentaram coliformes totais. No poço 4 , foram encontrados coliformes totais na maioria das amostras (80\%) do período chuva. No entanto, a presença de coliformes totais nesse tipo de fonte é tolerada na ausência de Escherichia coli (BRASIL, 2004). Sendo assim, são consideradas fora do padrão somente as amostras contendo E. coli, ou seja, $20 \%$ das amostras de seca dos poços 2 e 6.

\section{CONCLUSÃO}

Em linhas gerais, para águas minerais, $37 \%$ das amostras estavam fora dos padrões de potabilidade e a maioria das amostras era proveniente de galões de 20 L. Os estudos mostram a necessidade de aplicação de boas práticas de fabricação e de cuidados com a proteção das fontes.

Para águas de poço, $2,8 \%$ das amostras foram encontradas fora do padrão microbiológico 
de potabilidade. Existe a necessidade de revisão dos padrões de potabilidade para água de poço, uma vez que as águas que estavam dentro dos padrões para os indicadores estabelecidos na legislação apresentaram outros indicadores que, por hora, não são controlados. Para a qualidade química, o limite estabelecido para nitrato não foi excedido, embora no período de seca a concentração de nitrato nos poços seja acentuada.

\section{REFERÊNCIAS}

AMARAL, L.A. Influência da precipitação pluviométrica nas características bacteriológicas, físicas e químicas da água de diferentes mananciais de abastecimento da cidade de Jaboticabal - SP. 1992. 107f. Tese (Doutorado em Saúde Pública/Saúde Ambiental)

- Faculdade de Saúde Pública, Universidade de São Paulo, São Paulo, 1992.

APHA. Standard methods for the examination of water and wastewater. 16.ed. New York, 1992.

BISCHOFBERGER, T. et al. The bacterial flora of non-carbonated, natural mineral water from the springs to reservoir and glass and plastic bottles. Int. J. Food Microbiol., v.11, p.51-72, 1990.

BLAKE, P.A. et al. Cholera in Portugal, 1974. I. Modes of transmission. American Journal of Epidemiology, v.105, p.337-343, 1977a.

BLAKE, P.A. et al. Cholera in Portugal. II. Transmission by bottled mineral water. American Journal of Epidemiology, v.105, p.344-348, 1977b.

BRASIL. Agência Nacional de Vigilância Sanitária. Resolução RDC n 274, de 22 de Setembro de 2005. Aprova o regulamento técnico para águas envasadas e gelo. Diário Oficial da República Federativa do Brasil, Brasília, 23 set.2005.

BRASIL. Agência Nacional de Vigilância Sanitária. Resolução RDC n 275, de 22 de Setembro de 2005. Aprova o regulamento técnico de características microbiológicas para água mineral natural e água natural. Diário Oficial da República Federativa do Brasil, Brasília, 23 set. 2005.

BRASIL. Ministério da Saúde. Portaria n. 518, de 25 março de 2004. Estabelece os procedimentos e responsabilidades relativos ao controle e vigilância da qualidade da água para consumo humano e seu padrão de potabilidade, e dá outras providências. Diário Oficial da República Federativa do Brasil, Brasília, 26 mar. 2004.

BURGE, S.H.; HUNTER, P.R. The survival of enteropathogenic bacteria in bottled mineral water. Riv. Ital. Ig., v.50, p.401-406, 1990.

CLARCK, J.A.; BURGER, C.A.; SABATINOS, L.E. Characterization of indicator bacteria in 
municipal raw water, drinking water, and new main water samples. Can. J. Microbiol., v.28, p.1002-1013, 1982.

FEWTRELL, L.; KAY, D.; WYER, M.; GODFREE, A.; O’NEILL, G. Microbiological quality of bottled water. Water Sci. Technol., v.35, p.47-53, 1997.

FURTADO, C. et al. Outbreaks of waterborne infectious intestinal disease in England and Wales, 1992-5. Epidemiol. Infect., v.121, p.109-119, 1998.

GELDREICH, E.E. The bacteriology of water. In: TOPLEY W. Microbiology and Microbial Infections. London: Arnold Pub, 1998. p.351-365.

HACH. Dr/2000 Spectrophotometer Instrument Manual for Use With Software Version 3. s.d.

JEENA, M.I. et al. Risk assessment of heterotrophic bacteria from bottled drinking water sold in Indian markets. Int J Hyg Environ Health, v.209, p.191-196, 2006.

KORZENIEWSKA, E. et al. Microbiological quality of carbonated and non-carbonated mineral water stored at different temperatures. Pol. J. Microbiol., v.54, p.27-33, 2005.

MINISTÉRIO DA SAÚDE. Disponível em: $<$ http://portal.saude.gov.br/portal/saude/visualizar_ texto.cfm?idtxt=24995>. Acesso em: 15 out 2006.

MCFETERS, G.A. et al. Comparative survival of indicator bacteria and enteric pathogens in well water. Applied Microbiology, v.27, p.823-829, 1974.

OBIRI-DANSO, K.; OKORE-HANSO, A.; JONES, K. The microbiological quality of drinking water sold on the streets in Kumasi, Ghana. Lett. Appl. Microbiol., v.37, p.334-339, 2003.

PAYMENT, P.; FRANCO, E. Clostridium perfringens and somatic coliphages as indicators of the efficiency of drinking water treatment for viruses and protozoan cysts. Applied and Environmental Microbiology, v.59, p.2418-2424, 1993.

SARTORY, D.P. et al. Evaluation of two media for membrane filtration enumeration of Clostridium perfringens from water. Lett. Appl. Microbiol., v.27, p.323-327, 1998.

VANIERI, D. et al. Microbiological evaluation of bottled non-carbonated ("still") water from domestic brands in Greece. Int. J. Food. Microbiol., v.107, p.68-72, 2005.

WARBURTON, D. et al. A further review of the microbiological quality of bottled water sold in Canada: 1992 - 1997 survey results. Int. J. Food Microbiol., v.39, p.221-226, 1998. 